RAD Conference Proceedings, vol. 2, pp. 55-58, 2017

www.rad-proceedings.org

a.00001 tht

\title{
DUST EFFECT ON OPTICALLY STIMULATED LUMINESCENCE DOSIMETRY
}

\author{
Şamil Osman Gürdalı* ${ }^{*}$ S. Sinan Keskin², Mehmet Tombakoğlu ${ }^{1}$
}

${ }^{1}$ Hacettepe University, Department of Nuclear engineering, Beytepe, Ankara, Turkey ${ }^{2}$ Marmara University, Department of Environmental Engineering, Kadıkoy, İstanbul, Turkey

\begin{abstract}
Optically stimulated luminescence dosimetry (OSLD) has been used for dose measurements in many different radiation fields for personal monitoring and medical and industrial applications. One of the most important advantages of the OSLD compared to thermoluminescence dosimetry (TLD) is the light source used to stimulate the crystal. On the other hand, there is a discrimination problem between the light used in a stimulation and the luminescence light obtained as a result of stimulation. To measure the correct dose value, the stimulation and luminescence light have to be discriminated precisely by using different optic filters such as UV blocking, long and short band filters. In addition, the OSL readers are calibrated under fixed conditions (normal operating condition of optic filters, light source, photomultiplier tube, etc). The measured dose values are very sensitive to changes in normal operating conditions. In this work, the dust buildup factor on the optic filters is studied to analyse the response of BeO OSL dosimeter system. The elemental composition of suspended dust was determined by using the literature given for samples obtained from different indoor locations in Turkey and abroad. The light transport algorithm is used to simulate BeO OSL dosimeter system's response with and without dust buildup by means of Monte Carlo photon transport technique. The Coherent and incoherent scattering of the light, as well as other photon interaction mechanisms, were explicitly modelled in Monte Carlo simulations. The dust buildup effects on OSL spectrum were investigated in detail as a function of dust thickness on the optic filters and elemental composition of the dust.
\end{abstract}

Key words: Optically Stimulated Luminescence Dosimetry (OSLD), Dosimetry, Dust effect, Monte Carlo simulation

DOI: $10.21175 /$ RadProc.2017.12

\section{INTRODUCTION}

The optically stimulated luminescence (OSL) method is used worldwide to measure the personal dose, patient dose, and it is also used in some applications such as dose measurement in irradiated food, luminescence dating, etc. The OSL measurement systems contain the stimulation light source and detection part of luminescence light from the exposed material. Optic filters are also used to discriminate the lights to measure luminescence light correctly [1]. Generally, the OSL systems (reader and eraser) are used in personal monitoring laboratories [2, 3], hospitals $[4,5]$ and research laboratories [6]. In these measurement locations, the systems are exposed to indoor dust throughout the time. In practical applications, quality assurance tests (QA) are performed periodically to overcome fluctuations of the dosimetry system [7]. The fluctuations of the system could be derived from lots of parameters (PMT, filters, led, etc.). So, QA test results show that only whole fluctuations of the dosimetry system but not distinguish from each other. Hence, the focus of this study is to show the dust effect on OSL decay curve for $\mathrm{BeO}$ crystal based OSL system using Monte Carlo method.

\section{METHODS}

In personal monitoring laboratories, different crystal based OSLD systems $\left(\mathrm{Al}_{2} \mathrm{O}_{3}: \mathrm{C}, \mathrm{BeO}\right)$ are used in service. In this study, $\mathrm{BeO}$ crystal based OSLD system is examined to show the dust effect on measurement dose values. The block diagram of the $\mathrm{BeO}$ crystal based OSLD reader is shown in Figure 1. As seen from this figure, the stimulation (UV blocking and Schott BG-39) and detection (Hoya-U340 or Schott DUG11X) filters are used to discriminate stimulation and luminescence lights. In addition, the most probable dust locations on filters (stimulation and detection) can also be seen in this figure. The $\mathrm{BeO}$ crystal based OSLD system was characterized by using the computer code system Monte Carlo simulation technique developed by Ş. O. Gürdal using [8]. In this study, the developed computer code system was used to simulate $\mathrm{BeO}$ crystal based OSLD system with and without dust build up. This computer code system consists of three main modules; irradiation, stimulation and detection. In the detection module, the light transport due to luminescence is modelled for BeO crystal, filter and PMT parts.

\footnotetext{
*sgurdal@hacettepe.edu.tr
} 
The main objective in this work is to determine the effects of indoor dust build up on filters by using computer code simulations that perform the dust content and thickness dependent analysis. In the first stage, a representative composition for the indoor dust particles was investigated using the relevant data given in literature $[9,10,11,12,13]$. Ambient air particulate matter (PM) is usually measured in two size fractions as $\mathrm{PM}_{2.5}$ (fine) and $\mathrm{PM}_{10}$ (coarse) modes. They indicate particles with equivalent diameters less than $2.5 \mu \mathrm{m}$ and $10 \mu \mathrm{m}$, respectively. Ambient dust particles contain organic carbon (OC), other organic material (OM), elemental carbon (EC), ammonium, nitrate, sulphate, soil dust, and trace elements. Among these, soil dust, sea salt, and trace elements components can be considered as the most variable ones from one study to another. Ratios of the other components can be considered comparatively constant and their weight percents can be adjusted with respect to soil dust, sea salt, and trace element contents. Considering this fact, $\mathrm{PM}_{2.5}$ and $\mathrm{PM}_{10}$ soil dust, sea salt, and trace element concentrations obtained from the indoor air environment of a hospital in Istanbul were used to obtain their total weight percentages [14]. Approximately 30 daily measurements were used for each of $\mathrm{PM}_{2.5}$ and $\mathrm{PM}_{10}$ modes to calculate the total weight percent of soil dust, sea salt, and trace element components in PM. Results indicated $23.8 \%$ and $16.4 \%$ weight percents for $\mathrm{PM}_{2.5}$ and $\mathrm{PM}_{10}$ modes, respectively. Using these percentages, the weight percents of the other particulate matter components were calculated from their relative abundances given in the literature as cited above. The results are presented in Table 1.

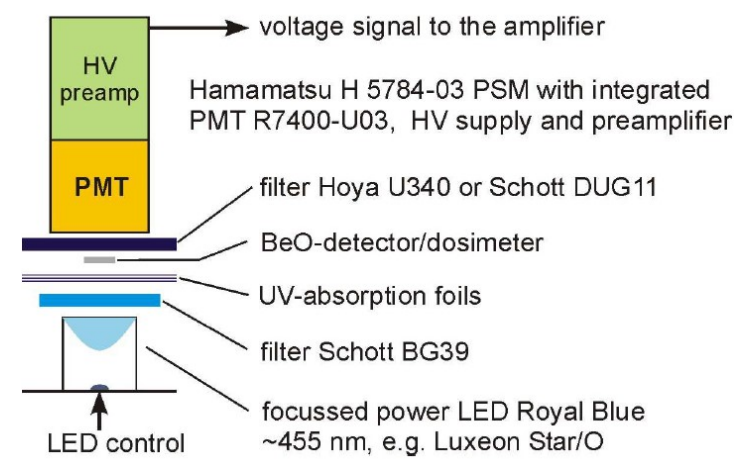

Figure 1. The block diagram of the $\mathrm{BeO}$ crystal based OSLD reader

After this stage, the macroscopic photon interaction cross sections were calculated by using the composition of dust and ENDF-VII photo-atomic data library [15]. The photo-atomic data show that coherent (Rayleigh) scattering is dominant for low energy photons (as in our case) for stimulation and detection photons having wavelengths $455 \mathrm{~nm}$ and $370 \mathrm{~nm}$, respectively. In the light of this information, only Rayleigh scattering interaction was included in Monte Carlo model to perform the photon transport in the dust regions.

\section{CALCUlations AND RESUltS}

The dust effect on BeO crystal based OSLD was investigated in two steps. In the first step, simulations were performed for $1 \mathrm{mSv}$ whole body dose $\left(\mathrm{H}_{\mathrm{p}}(10)\right)$ without dust. OSL-decay curves were obtained by Monte Carlo simulation and compared with experimental data as given in Figure 2. In this figure, for $1 \mathrm{mSv}$ whole body dose, the simulation results and experimental data are given for OSL counts as a function of time. Accredited (according to ISO IEC 62387-1) BeOSL OSL dosimeter (Dosimeter $\mathrm{ID}=8061090)$ and reader were used in experiments.

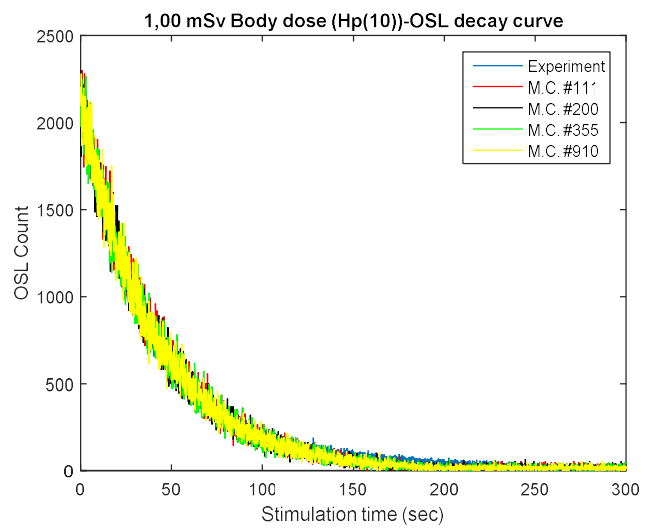

Figure 2. OSL decay curves for $1 \mathrm{mSv}$ whole body dose

In practical applications, the dose value is calculated by using first five seconds data of the OSLdecay curve [16]. Using the experimental data and simulation results, dose values were determined from OSL-curves. Since the simulation model is stochastic, the frequency of the dose values obtained by simulations is given by a normal distribution and resulting frequency distribution is given in Figure 3 for 1000 Monte Carlo simulation.

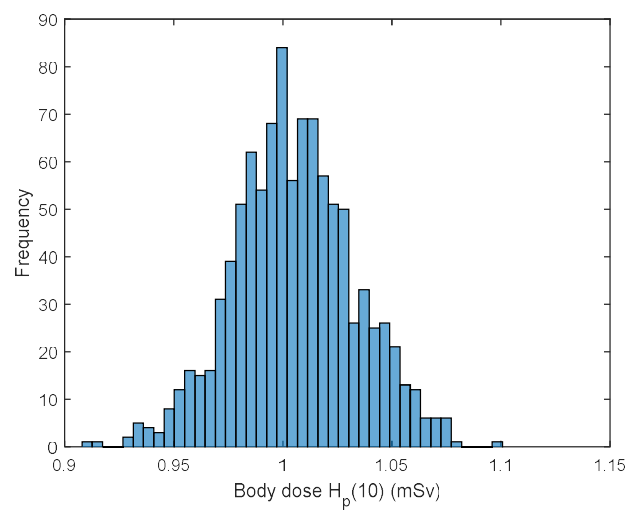

Figure3. Frequency distribution of dose, obtained by simulations for $1 \mathrm{mSv}$ whole body dose

In the simulations, to account for the dust buildup, the composition of indoor dust for $\mathrm{PM}_{2.5}$ and $\mathrm{PM}_{10}$ modes obtained as explained in Section 2 and tabulated in Table 1 were used. 
Table 1. Composition of PM2.5 and PM10 modes

\begin{tabular}{|c|c|c|}
\hline Composition & w/o \% in $\mathrm{PM}_{2.5}$ & $\mathrm{w} / \mathrm{o} \%$ in $\mathrm{PM}_{10}$ \\
\hline $\mathrm{OC}$ & 39.58 & 47.21 \\
$\mathrm{SO}_{4}$ & 15.83 & 14.74 \\
$\mathrm{NH}_{4}$ & 6.33 & 6.09 \\
$\mathrm{NO}_{3}$ & 6.33 & 7.88 \\
$\mathrm{H}_{2} \mathrm{O}$ & 5.54 & 5.52 \\
$\mathrm{C}$ & 2.38 & 2.14 \\
$\mathrm{Na}$ & 4.96 & 3.73 \\
$\mathrm{Mg}$ & 0.75 & 0.77 \\
$\mathrm{Al}$ & 1.98 & 1.57 \\
$\mathrm{~K}$ & 1.95 & 1.08 \\
$\mathrm{Fe}$ & 1.96 & 1.74 \\
$\mathrm{Ca}$ & 7.43 & 4.38 \\
$\mathrm{Si}$ & 3.38 & 2.66 \\
$\mathrm{Zn}$ & 1.25 & 0.42 \\
$\mathrm{~Pb}$ & 0.10 & 0.03 \\
\hline
\end{tabular}

Macroscopic coherent cross sections were calculated for $\mathrm{PM}_{2.5}$ and $\mathrm{PM}_{10}$ modes by using the compositions given in Table 1 at stimulation $(455 \mathrm{~nm})$ and luminescence $(370 \mathrm{~nm})$ wavelengths and results are presented in Table 2.

Table 2: Macroscopic coherent cross sections forPM $\mathrm{PM}_{2.5}$ and $\mathrm{PM}_{10}$

\begin{tabular}{|c|c|c|}
\hline Dust Type & $\sum_{c o h}^{S t i}\left(\mathrm{~cm}^{-1}\right)$ & $\sum_{c o h}^{L u m}\left(\mathrm{~cm}^{-1}\right)$ \\
\hline $\mathrm{PM}_{2.5}$ & 0.0119 & 2.637 \\
$\mathrm{PM}_{10}$ & 0.0109 & 3.007 \\
\hline
\end{tabular}

The calculated macroscopic coherent cross sections indicate that the interaction probability of photons used in stimulation with buildup dust on the filters is very low compared to that of luminescence photons. Therefore, time dependent OSL decay counts are more sensitive to the transport of luminescence photons. For this reason, in the Monte Carlo model, the photon transport in buildup dust on the stimulation filter was ignored. Finally, Monte Carlo simulations were performed to study the effects of dust composition and thickness on the filter which is used between OSL crystal and PMT tube. In Figure 4, OSL counts obtained by Monte Carlo simulations with dust buildup of $\mathrm{PM}_{2.5}$ (2.5 micrometre thickness) and PM10 (10 micrometre thickness) modes together with experimental data without dust buildup are given. The results show that OSL counts obtained from simulations with dust buildup are less than the experimental counts. To determine dose values, these data are utilized in the dose calculation algorithms. The resulting dose values obey a normal distribution function due to stochastic processes from the beginning to end of irradiation and radiation transport processes. The frequency distributions of dose values obtained with and without dust buildup are given in Figure 5 .
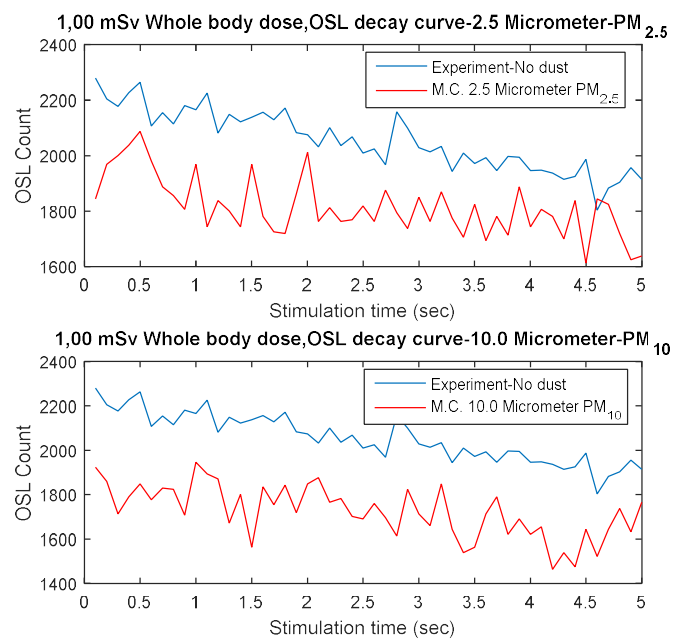

Figure 4. OSL decay curve for $1 \mathrm{mSv}$ whole body dose as a function of time (first 5 seconds interval)
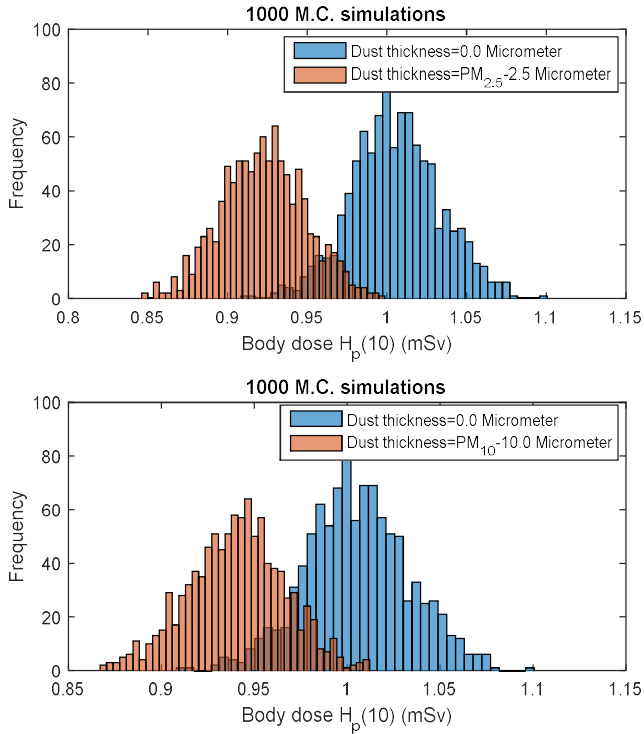

Figure 5. Frequency distributions of dose for $1 \mathrm{mSv}$ whole body dose with and without dust buildup

In Table 3 and 4, mean dose values and their standard deviations obtained from simulations are given as a function of dust thicknesses for $\mathrm{PM}_{2.5}$ and $\mathrm{PM}_{10}$ modes, respectively. The results show that, due to the dust buildup on the detection filter, the mean dose response of the system is decreased compared to the mean dose response of the system without dust buildup. 
Table 3. Mean dose values as a function of dust thickness for $\mathrm{PM}_{2.5}$ mode

\begin{tabular}{|c|c|c|}
\hline $\begin{array}{c}\text { Dust thickness } \\
\text { (micrometre) }\end{array}$ & $\begin{array}{c}\text { Mean dose } \\
\text { value }(\mathrm{mSv})\end{array}$ & $\begin{array}{c}\text { Standard } \\
\text { Deviation of dose }\end{array}$ \\
\hline 2.5 & 0.9223 & 0.0261 \\
25 & 0.9184 & 0.0254 \\
100 & 0.8770 & 0.0237 \\
\hline
\end{tabular}

Table4. Mean dose values as a function of dust thickness for $\mathrm{PM}_{10}$ mode

\begin{tabular}{|c|c|c|}
\hline $\begin{array}{c}\text { Dust thickness } \\
\text { (micrometre) }\end{array}$ & $\begin{array}{c}\text { Mean dose } \\
\text { value }(\mathrm{mSv})\end{array}$ & $\begin{array}{c}\text { Standard } \\
\text { Deviation of dose }\end{array}$ \\
\hline 10 & 0.9404 & 0.0257 \\
100 & 0.9237 & 0.0250 \\
400 & 0.8597 & 0.0236 \\
\hline
\end{tabular}

\section{CONCLUSION}

Results obtained in this study indicate that:

- $\quad$ The dust build up on stimulation filters does not influence the measured dose values for $\mathrm{BeO}$ crystal based OSLD system.

- The dust build up on detection filters has a decreasing impact on the measured dose values and this decrease depends on the dust composition and thickness.

In conclusion, the quality control (QC) and quality assurance (QA) tests have to be performed periodically to identify and control fluctuations on the dose response of OSLD system.

\section{REFERENCES}

1. E. G. Yukihara, S. W. S. McKeever, "Theory and Practical Aspects," in Optically Stimulated Luminescence: Fundamentals and Applications, Chichester, UK: John Wiley-and Sons Inc., 2011, ch. 2, sec. $2.4 \cdot 3$, pp. $67-68$.

DOI: $10.1002 / 9780470977064 . c h 2$

2. OSL Personal Dosimetry System, Landauer Inc., Glenwood (IL), USA.

Retrieved from: http://www.landauer.com/Industry/Products/Dosimet ers/Dosimeters.aspx Retrieved on: Nov. 20, 2016

3. BeOSL Personal Dosimetry System, Dosimetrics GmbH, Munich, Germany.

Retrieved from:

http://www.dosimetrics.de/productsservices/ Retrieved on: Nov. 20, 2016

4. J. Henniger et al., "The BeOMaxsystem- Dosimetry using OSL of $\mathrm{BeO}$ for several applications," Radiation Measurements, vol. 56, pp. 324-327, Sep. 2013.

DOI: 10.1016/j.radmeas.2013.01.069
5. Microstar ii Medical dosimetry system, Landauer Inc. Glenwood (IL), USA.

Retrieved from:

http://landauer.com/uploadedFiles/special/microSTA

RiiBrochure.pdf

Retrieved on: Nov. 20, 2016

6. Guide to "The Risø TL/OSL reader", DTU Nutech, Roskilde, Denmark, 2015.

Retrieved from:

http://www.usu.edu/geo/luminlab/Reader.pdf

Retrieved on: Nov. 20, 2016

7. "BeOSL Dosimetry System-QA Test Results," RADKOR Personal Monitoring Lab., Ankara, Turkey, 2016.

8. Ş. O. Gürdal, "Simulation of Optically Stimulated Luminescence Dosimetry Systems via Monte Carlo Method," Ph.D. dissertation, Nuclear Eng. Dept., Hacettepe University, Ankara, Turkey, 2016.

9. O. Schmid et al., "Derivation of the Density and Refractive Index of Organic Matter and Elemental Carbon from Closure between Physical and Chemical Aerosol Properties," Environmental Science Technology, vol. 43, no. 4, pp. 1166-1172, Feb. 2009. DOI: $10.1021 /$ es800570p PMid: 19320175

10. L. Tofful and C. Perrino, "Chemical Composition of Indoor and Outdoor PM2.5 in three Schools in the City of Rome," Atmosphere, vol. 6, no. 10, pp. 1422-1443, Sep. 2015.

DOI: $10.3390 /$ atmos6101422

11. K. Na and D. R. Cocker, "Organic and Elemental Carbon Concentrations in Fine Particulate Matter in Residences, Schoolrooms, and Outdoor Air in Mira Loma, California,” Atmospheric Environment, vol. 39, no. 18, pp. 3325-3333, Jan. 2005. DOI: 10.1016/j.atmosenv.2005.01.054

12. J. L. Mauderly and J. C. Chow, "Health Effects of Organic Aerosols," Inhalation Toxicology, vol. 20, no. 3, pp. 257-288, Mar. 2008. DOI: $10.1080 / 08958370701866008$ PMid: 18300047

13. M. Hu et all, "Estimation of Size-Resolved Ambient Particle Density Based on the Measurement of Aerosol Number, Mass and Chemical Size Distributions in the Winter in Beijing," Environmental Science \& Technology, vol. 46, no. 18, pp. 9941-9947, Sep. 2012. DOI: $10.1021 / \mathrm{es} 204073 \mathrm{t}$ PMid: 22458861

14. S. Kılıç, "Determination of Indoor Air Particulate Matter Mass and Elemental Concentrations in a Selected Hospital," M.S. thesis, Environmental Eng. Dept., Marmara University, Istanbul, Turkey, 2010.

15. ENDF/B-VII Incident-Gamma Data, Los Alamos National Lab., Los Alamos (NM), USA.

Retrieved from: https://t2.lanl.gov/nis/data/endf/endfvii-g.html Retrieved on: Nov. 25, 2016

16. "BeO OSL Dosimetry System," Helmholtz Zentrum, Munich, Germany, 2009. 